\title{
PRIMEIRA APROXIMAÇÃO DA GEOGRAFIA INSTITUCIONAL BRASILEIRA COM A GEOGRAFIA NORTE-AMERICANA: UMA ANÁLISE A PARTIR DA OBRA DE JORGE ZARUR
}

\section{FIRST APPROACH OF BRAZILIAN INSTITUTIONAL GEOGRAPHY WITH AMERICAN GEOGRAPHY: AN ANALYSIS FROM THE WORK OF JORGE ZARUR}

\author{
Mônica Sampaio Machado' \\ Universidade do Estado do Rio de Janeiro (UERJ), Rio de Janeiro, RJ, Brasil, monica.sampaio@pq.cnpq.br \\ Marcela Bonelli Zarur \\ Universidade do Estado do Rio de Janeiro (UERJ), Rio de Janeiro, RJ, Brasil, marcelazarur@gmail.com
}

\begin{abstract}
RESUMO
Este trabalho discute a aproximação da Geografia produzida nos Estados Unidos com a Geografia feita no Brasil, nas décadas de 1940 e 1950. O geógrafo Jorge Zarur é aqui trazido como um importante personagem dessa aproximação. Um panorama da política externa brasileira, naquelas décadas, inicia este artigo. Em seguida serão apresentados o quadro institucional do sistema geográfico oficial brasileiro e seus principais personagens. Por último a vida e a obra de Zarur, assim como seus principais interlocutores, serão explorados. Uma síntese da contribuição do autor à Geografia brasileira será exposta, salientando as características recebidas da influência norte-americana.
\end{abstract}

Palavras-chave Geografia Brasileira; pan-americanismo, geógrafos brasileiros; IBGE; Jorge Zarur.

\begin{abstract}
This paper discusses the approach of Geography produced in the United States with geography made in Brazil in the 1940s and 1950. The geographer Jorge Zarur is brought here as an important character of this approach. An overview of Brazilian foreign policy in those decades, begins this article. Then will be presented the institutional framework of the Brazilian official geographic system and its main characters. Finally the life and work of Zarur, as well as its main partners will be explored. A summary of the author's contribution to the Brazilian Geography is exposed, highlighting the characteristics of American influence received.
\end{abstract}

Keywords: Brazilian geography; Pan-Americanism, Brazilian geographers; IBGE; Jorge Zarur.

Artigo recebido para publicação em outubro de 2015

Artigo aceito para publicação em dezembro de 2015

\section{INTRODUÇÃO}

Grande parte da literatura e das discussões a cerca da história e do desenvolvimento da ciência geográfica brasileira institucionalizada tem sido conduzida, predominantemente, a partir da abordagem paradigmática. O debate epistemológico e historiográfico da Geografia no Brasil vem sendo, na sua maioria, pautado pela identificação e classificação de autores, temas, objetivos, metodologias, etc. em grandes padrões científicos e filosóficos, como, por exemplo, o positivista clássico, o neopositivista, o marxista, o hermenêutico, o pós-moderno, ou qualquer outro modelo.

\footnotetext{
${ }^{1}$ Bolsista Produtividade em Pesquisa CNPq - 2
} 
Da mesma maneira, é comum encontrar classificações estabelecidas a partir de cortes temporais, como forma de identificação de discursos e práticas científicas dominantes no tempo. Assim, por exemplo, como nas cinco primeiras décadas do século XX grande foi a influência do positivismo clássico, os estudos e autores da Geografia desse período costumam ser identificados e classificados como positivistas clássicos. Associação similar vai ser estabelecida nas três décadas seguintes, quando os estudos e os geógrafos passam a ser classificados como neopositivistas, em função da influência do positivismo lógico-formal nas práticas científicas e acadêmicas.

Não há, entretanto, nada de errado com essa forma de abordagem e de entendimento da dinâmica científica da Geografia. De fato, cada modelo de produção do conhecimento científico possui uma base filosófica predominante que dirige as formas de pesquisa, observação e demonstração dos resultados, interferindo, igualmente, na adoção e desenvolvimento de teorias, métodos, valores e técnicas de investigação. Esses modelos são datados, são produtos históricos, ou seja, exercem influência em um dado período. Portanto, os paradigmas orientam e influenciam toda a prática científica em um dado espaço de tempo.

Nesse sentido, quando falamos em Geografia positivista clássica, temos em mente não apenas algumas práticas de pesquisa desenvolvidas e utilizadas pela ciência geográfica clássica ou tradicional, como também os limites do conhecimento geográfico, estabelecido pela filosofia positivista com a renúncia da metafisica. Características gerais que podem ser identificadas, principalmente, nos estudos geográficos brasileiros no período em que o modelo de conhecimento científico estava orientado pelo positivismo clássico, ou seja, nas cinco primeiras décadas do século XX.

Contudo, quando ordenamos a produção do conhecimento geográfico em períodos e agrupamos estudos e geógrafos sob a mesma classificação, o mesmo paradigma, acabamos equalizando os trabalhos e abdicando ao conhecimento pormenorizado. Se por um lado temos a ideia do todo, da dinâmica geral, por outro, desconhecemos autores, temas, metodologias, histórias, espaços, memórias, enfim, ignoramos as singularidades, as contribuições e os limites da produção científica geográfica. 
Neste artigo, nossa opção para o tratamento da ciência geográfica difere da abordagem paradigmática e é fruto das atividades que vêm sendo desenvolvidas no Grupo de Pesquisa Geografia Brasileira: História e Política (GeoBrasil), principalmente, a partir do projeto de pesquisa Dicionário dos Geógrafos Brasileiros. Com base em um extenso levantamento bibliográfico e documental, personagens da Geografia brasileira vêm sendo levantados, redescobertos e estudados, não apenas suas biografias, como também suas obras. $\mathrm{O}$ esforço realizado tem como objetivo oferecer uma pequena contribuição à história e memória da Geografia brasileira, a partir da identificação e análise da vida e obra dos seus autores.

Assim, na pesquisa realizada sobre os primeiros geógrafos brasileiros do Instituto Brasileiro de Geografia e Estatística (IBGE), em finais da década de 1930 e início de 1940, nos deparamos com vários nomes ainda muito pouco explorados e conhecidos pelo campo científico geográfico da atualidade, dentre eles, trazemos aqui, o geógrafo Jorge Zarur ${ }^{2}$. A análise da atuação profissional de Zarur tem revelado a singularidade de sua articulação política e de sua obra, possibilitando um olhar diferenciado e mais detalhado de sua contribuição à Geografia, enriquecendo e dialogando com a classificação que inclui o autor no rol dos geógrafos positivistas clássicos, assim como vários outros geógrafos "ibegeanos" do período.

A singularidade do trabalho de Zarur só pode ser percebida com o estudo detalhado de seus artigos, de suas atuações institucionais e a partir do levantamento e análise documental. Chama especial atenção a influência da Geografia norte-americana na obra e na atuação do autor, duas décadas antes da eclosão do neopositivismo de matriz norte-americana no País. Na realidade, a partir dos trabalhos realizados por Zarur entre 1941 e 1957, a primeira aproximação norte-americana com a Geografia brasileira

\footnotetext{
${ }^{2}$ Dois trabalhos publicados sobre Zarur merecem menção. O primeiro é do professor Horiestes Gomes, no Boletim Goiano de Geografia, em 1997, Jorge Zarur: "um geógrafo moderno". Gomes apresenta um panorama sobre as principais obras e contribuições de Zarur e aponta que sua obra foi inovadora na década de 50 no Brasil, uma vez que passou a defender uma Geografia fundamentada não em bases empíricas, mas uma ciência prática e utilitária. O segundo trabalho é do professor Francisco Veloso Filho, da Universidade do Piauí, na Revista Equador (UFPI), Análises Geográficas do espaço regional: referências conceituais, metodológicas e estudos aplicados no Brasil. Apesar de Veloso Filho não abordar exclusivamente a obra do Zarur, pois seu objetivo é apresentar e discutir os diferentes estudos regionais no Brasil, ele aponta as principais características e as especificidades da abordagem regionalista do autor.
} 
pode ser observada e avaliada, assim como sua defesa pelo método regional resultado da influência de Alfred Hettner, Richard Hartshorne, Leo Waibel, Clarence Jones e Preston James. Os temas e os recortes espaciais das obras do autor, conforme serão vistos, podem ser explicados pela mencionada aproximação.

Buscando apresentar a avaliação realizada da obra de Zarur, este trabalho está organizado em três partes. A primeira oferece um breve panorama da política externa brasileira, das décadas de 1940 e 1950, com intuito de salientar adesão do País aos propósitos pan-americanistas estadunidenses e clarificar suas opções no período. Após essa contextualização, um quadro institucional do sistema geográfico oficial brasileiro e seus principais personagens será tecido, com objetivo de situar Zarur e chamar atenção para seu papel articulador. Em seguida serão apresentadas e analisadas a vida e a obra do autor, incluindo seus principais interlocutores. A intenção aqui é tanto apresentar os estudos de Zarur quanto qualificar e localizar as origens e características de suas influências. Uma síntese da contribuição de Jorge Zarur à Geografia brasileira será exposta, salientando as características da influência norte-americana em suas obras.

\section{O pan-americanismo estadunidense e a política externa brasileira nas décadas de 1940 e 1950}

Nas décadas de 1930 e 1940 os Estados Unidos passaram a desenvolver e aplicar estratégias e táticas internacionais mais ofensivas para consolidar eu papel de potência mundial. Ampliaram efetivamente sua influência política, econômica e cultural não apenas no Brasil, mas em toda a América Latina. Com apoio do primeiro Governo Vargas (1930-1945), iniciativas econômicas e culturais foram planejadas e executadas no Brasil pela diplomacia norte-americana, principalmente a partir da embaixada estadunidense localizada na cidade Rio de Janeiro, então capital federal. Na década de 1940, por exemplo, passaram a ser patrocinadas viagens de brasileiros aos Estados Unidos e de especialistas estadunidenses ao Brasil, além do incentivo financeiro para colaborações entre instituições educacionais e de pesquisa entre os dois países. Entre essas instituições estavam universidades, jornais, estações de rádio, fundações culturais e científicas, editoras, associações profissionais e 
empresas. Entre os indivíduos constavam jornalistas, artistas, diretores de cinema, escritores, professores, cientistas, militares, diplomatas e empresários ${ }^{3}$.

Mesmo o Governo brasileiro colaborando com as nações do Eixo, o então Ministro das Relações Exteriores de Vargas, Oswaldo Aranha, já em 1938, anunciava igualmente apoio aos Estados Unidos em seu projeto de potência mundial, em troca da ajuda destes a supremacia do Brasil na América do Sul. Como para a supremacia brasileira era necessário seu fortalecimento político, econômico e militar, a aliança estabelecida com os norte-americanos buscou consolidar a centralização e modernização do Estado e industrializar o País. Conhecedor da importância brasileira para a realização da política panamericana estadunidense, tanto na defesa do hemisfério e do Atlântico Sul quanto no fornecimento de matérias-primas, minerais e produtos tropicais, Vargas obtém dos norte-americanos não só aporte técnico, como também financeiro.

No ano de 1940, o presidente Franklin Roosevelt criou um órgão para lidar com os assuntos econômicos e culturais interamericanos dos Estados Unidos. Sob responsabilidade de Nelson Rockefeller, o órgão foi denominado de Office for the Coordination of Commercial and Cultural Relations between the American Republics. Um ano mais tarde, sua denominação mudou para Office of the Coordinator of Inter-American Affairs ficou assim conhecido até o final da Guerra. Formalmente, o órgão foi criado com objetivo de aumentar a solidariedade hemisférica e a cooperação interamericana. Entretanto, na prática, foi um instrumento utilizado pelos Estados Unidos para enfrentar os desafios internacionais, eliminar a influência do Eixo, consolidar seu poder como Grande Potência e assegurar a posição de liderança nas Américas ${ }^{4}$.

Com a entrada dos EUA na Guerra, em 1941, a atuação norte-americana sobre a América Latina amplia-se. Em de 1942 o Brasil também decreta estado de guerra a favor dos Aliados e romper relações diplomáticas e comerciais com a Alemanha, Itália e Japão. Na realidade apesar da simpatia de

\footnotetext{
${ }^{3}$ MOURA, Gerson, 2012, p.78.

${ }^{4}$ MOURA, Gerson, 2012, p.57-62.
} 
Getúlio Vargas especialmente por Mussolini, o Brasil vinha se mantendo politicamente neutro até então. Sua política externa era conhecida como pendular, ora aproximava-se do Eixo, ora dos Aliados. Entretanto, aos poucos os Estados Unidos foram intensificando os esforços de sedução para com o Brasil, não se restringindo a conversas diplomáticas, mas incluindo apoio financeiro tecnológico para a instalação da indústria de base no País. Essa política pendular, teria sido o objetivo de Getúlio para valorizar a adesão brasileira aos Aliados ${ }^{5}$.

Ainda no primeiro Governo Vargas, foram criadas empresas que viraram ícones do nacionalismo brasileiro, com financiamento norte-americano, a Companhia Siderúrgica Nacional, a então Vale do Rio Doce e o Conselho Nacional do Petróleo, embrião da Petrobras, criada posteriormente, no seu segundo Governo (1951-1954), em 1953.

Com o fim da Guerra, aumenta a ingerência dos Estados Unidos nos negócios dos países americanos, estendendo-se a Guerra Fria à América Latina. Em 1947 o Brasil rompe relações com a então União Soviética e apoia claramente os Estados Unidos. Condição que foi sendo mantida durante a década de 1950, tanto no segundo Governo Vargas, como no Governo Juscelino Kubitschek, que apesar de buscar independência política com relação aos norte-americanos, dependia de seus capitais para financiar seu projeto para o Brasil.

A ofensiva estadunidense no Brasil, nas décadas de 1940 e 1950, alcança também a esfera científica e educacional. Nos anos iniciais da Segunda Guerra a influência norte-americana se evidencia claramente nas relações científicas e institucionais entre Brasil e Estados Unidos, fruto dos programas empreendidos pelas agências e instituições norte-americanas ${ }^{6}$. A situação de guerra em território europeu acabou também favorecendo essa ofensiva não apenas inviabilizando a ida dos brasileiros, especialmente para Alemanha e França, mas limitando a influência europeia em território brasileiro, principalmente dos franceses, que vinham atuando nas universidades e centros de pesquisa e

\footnotetext{
${ }^{5}$ MENDONÇA, Sônia Regina de, 1990, p.327-350.

${ }^{6}$ Em 1951 o CNPq e a Capes foram criados. As universidades brasileiras receberam significativos aportes financeiros desses órgã os e de instituições internacionais, como Fundação Rockfeller e Kellog. (MACHADO, Mônica, 2009, p.101-102
} 
planejamento desde de 1934, fruto das missões universitárias francesas coordenadas por Georges Dumas.

Como parte dos esforços de aproximação do Brasil e de proteção da influência dos países do Eixo, os norte-americanos introduziram e fomentaram no País novas estratégias e processos de aprendizagem profissional, que incluíam métodos e técnicas na universidade, cursos profissionalizantes e bolsas de estudo para estágio nos Estados Unidos, oferecidas para universitários e para profissionais ligados às instituições brasileiras de ensino, pesquisa e planejamento. Dentre essas instituições, uma vez que constituíam importantes órgãos do sistema geográfico oficial brasileiro naquelas duas décadas, cabem destaque o Instituto Brasileiro de Geografia e Estatística (IBGE), a Universidade do Brasil, a Associação dos Geógrafos Brasileiros (AGB) e a Sociedade Brasileira de Geografia.

Durante a Segunda Guerra agências de inteligência americana empregaram geógrafos importantes para serviços de levantamento, mapeamento e análise de dados e informações estratégicas para atuação e operações durante o conflito. As agências americanas Office of Strategic Service (OSS) e Army Map Service (AMS), em Washington, DC, contrataram os geógrafos Cotton Mather, Clarence F. Jones, Preston James e Richard Hartshorne ${ }^{7}$. Destes os três últimos exerceram influência na Geografia brasileira das décadas de 1940 e 1950, especialmente em Jorge Zarur, que entre 1943 e 1945, trabalhou durante 18 meses no National Planning Association, Washington, DC, em um grande projeto que compreendia toda a América Latina, sob orientação de Clarence Jones e Preston James, dentre outros ${ }^{8}$.

\section{Instituições do sistema geográfico oficial brasileiro e seus principais personagens, 1930 e 1950}

Na modernização do Estado brasileiro promovida no primeiro Governo Vargas são criadas comissões, conselhos, departamentos, institutos, companhias, fundações, planos de desenvolvimento econômico e

${ }^{7}$ ALMEIDA, Roberto Schmidt, 2000, p.145

${ }^{8}$ ZARUR, Jorge. A Geografia: ciência moderna a serviço do homem. RBG, IBGE, 1944, v.6, n3, p.316-317 
cultural, promulgadas leis e decretos, enfim, são geradas e postas em prática várias instituições e medidas de controle e desenvolvimento econômico e cultural de âmbito nacional. Há uma grande reforma ministerial e várias instituições federais foram criadas e aglutinadas na cidade do Rio de Janeiro, então capital da República, fortalecendo ainda mais a histórica condição de capitalidade. O Rio de Janeiro passava cada vez mais a atrair intelectuais e diversos profissionais de todo o Brasil e de várias partes do mundo. As instituições federais aqui implantadas movimentavam recursos técnicos, humanos e financeiros que não existiam em outras cidades brasileiras naquelas décadas.

Nos cinco anos iniciais da década de 1930, no que tange diretamente o sistema geográfico oficial brasileiro foram criadas no Rio de Janeiro duas importantes instituições: a Universidade do Distrito Federal (UDF) (criada em 1935 e extinta em 1939, tendo seus cursos transferidos para a Universidade do Brasil, criada em 1937, atualmente Universidade Federal do Rio de Janeiro) onde foi implantado o segundo curso universitário de Geografia do País, em 1935 (o primeiro foi em 1934, em São Paulo, na USP); o Conselho Nacional de Geografia (CNG)/Instituto Brasileiro de Geografia e Estatística (IBGE), em 1938. ${ }^{9}$ Já havia no Rio de Janeiro, como heranças do Brasil Império, a Sociedade Brasileira de Geografia ${ }^{10}$ e o Instituto Histórico e Geográfico Brasileiro (IHGB).

Além dessas instituições diretamente relacionadas à Geografia, já existiam no Rio de Janeiro importantes acervos documentais e bibliográficos e instituições de formação e debate acadêmico que muito impulsionaram a ciência geográfica, como a Biblioteca Nacional, o Gabinete Real Português, o Arquivo Nacional, a Academia Brasileira de Letras (ABL), a Academia Brasileira de Ciências e o Colégio Pedro II. Alunos, professores e pesquisadores interessados no saber geográfico eram atraídos e transitavam por essas instituições.

\footnotetext{
${ }^{9}$ O IBGE historicamente foi organizado em janeiro de 1938, pela junção do Conselho Nacional de Estatística, criado em 1936 , oriundo do Instituto Nacional de Estatística, criado em 1934, com o Conselho Nacional de Geografia, implantado em 1937. Entretanto oficialmente a criação do IBGE ficou estabelecida em 29 de maio de 1936, ocasião em que foi regulamentada a profissão de geógrafo (PENHA, 1993, p.19). Sobre a criação e história do IBGE consultar PENHA, Eli Alves, 1993, e, ALMEIDA, Roberto Schmidt, 2000.

${ }^{10}$ A Sociedade Brasileira de Geografia foi criada em 1883, com a denominação de Sociedade de Geografia do Rio de Janeiro. Foi uma importante entidade que reunia diversos intelectuais, políticos, cientistas e que exerceu grande contribuição para o reconhecimento do território brasileiro, a formação de professores e a promoção do desenvolvimento do saber geográfico no Brasil.
} 
Fora do Rio de Janeiro, mas como parte importante do sistema geográfico brasileiro oficial, estava o recém-criado Curso de Geografia da Universidade de São Paulo. Embora implantada pela oligarquia paulista, derrotada pela Revolução de 1930 e pelo confronto constitucionalista de 1932, portanto, em oposição aos projetos centralizadores de Getúlio, a Universidade de São Paulo, através da Faculdade de Filosofia e do Curso de Geografia vai participar ativamente da estruturação da Geografia institucionalizada no País. Primeiramente trazendo para a cátedra de Geografia Humana dois geógrafos franceses Pierre Deffontaines e Pierre Monbeig ${ }^{11}$. Ambos os geógrafos foram também muito importantes para a implantação do CNG/IBGE no Rio de Janeiro. Exerceram também papel importante na implantação da Geografia universitária e da Associação dos Geógrafos Brasileiros (AGB) no Rio de Janeiro e em São Paulo. Foram igualmente responsáveis pela introdução e o fortalecimento da escola francesa de Geografia no Brasil ${ }^{12}$.

A formação do CNG/IBGE, a adesão do Brasil à União Geográfica Internacional (UGI), a implantação da AGB e a consolidação dos primeiros anos dos cursos universitários de Geografia, em São Paulo e no Rio de Janeiro, ocorrem durante os anos de 1934 e 1938 e foram resultados das articulações estabelecidas entre Pierre Deffontaines, Pierre Monbeig e Christóvam Leite de Castro, então secretário do CNG, entre 1937-1950 ${ }^{13}$.

11 Deffontaines também organizou e implantou em São Paulo a Associação de Geógrafos Brasileiros (AGB) em 1935. No ano seguinte veio para o Rio lecionar na Universidade do Distrito Federal, implantando também aqui AGB. Pierre Monbeig assumiu a cátedra e a presidência da AGB em São Paulo. A AGB nasceu vinculada à cadeira de Geografia da Universidade de São Paulo e reuniu estudiosos e amador es da Geografia, animados pela paixão de descobrir e conhecer o país. Contribuíram para o fortalecimento da AGB nomes como Luís Flores de Moraes e Rêgo, Caio Prado Junior, Mário Travassos, entre outros. (ANAIS DA ASSOCIAÇÃO DE GEÓGRAFOS BRASILEIROS, 1946, p.3-6).

12 BERNARDES, Nilo, 1982.

13 "Na década de 1930, o Governo brasileiro começou a trazer professores franceses, entre eles o Deffontaines, o Monbeig e o De Martonne, que fez uma visita e escreveu um trabalho sobre a Geografia física tropical. O De Martonne era a autoridade na União Geográfica Nacional. Ele e o Pierre Deffontainnes começaram a vender a ideia de o Brasil aderir à União Geográfica Internacional, isso em 1937 e 1938 . O Ministro das Relações Exteriores na época, Macedo Soares Guimarães, propôs ao Getúlio aderir à União Geográfica internacional, o que foi feito por decreto. Esse decreto estabeleceu a criação de um órgão mediador, que se chamou Conselho Nacional de Geografia. A formação do IBGE se efetivou pela união do CNG com o Conselho Nacional de Estatística. O então Instituto Brasileiro de Estatística era, na verdade, o Instituto Brasileiro de Geografia e Estatística. Há, assim, uma influência externa para a criação do próprio IBGE. Com isso, o IBGE se torna o centro da relação Brasil e UGI. Durante muito tempo tanto a pesquisa geográfica quanto as relações internacionais com o mundo acadêmico geográfico se fizeram via IBGE.” (Entrevista Pedro Geiger, realizada em 31 de outubro de 2001, por Mônica Machado, disponível em http://www.grupogeobrasil.com.br/usuario//pedro_geiger//pedro_geiger_geobiografia_2.pdf) 
Enquanto em São Paulo Pierre Monbeig, que havia substituído Deffontaines na USP, criava a o núcleo paulista de Geografia, Deffontaines criava no Rio outro ramo, até então independente. Um suporte fundamental às atividades de Deffontaines, principalmente nas atividades da AGB no Rio, foi dado por Cristóvão Leite de Castro, com a criação do CNG/IBGE ${ }^{14}$.

Entre 1935 e 1939 as instituições mais ativas e modernas do ponto de vista científico da Geografia no Rio de Janeiro eram o CNG/IBGE, a AGB-Rio e a Universidade do Distrito Federal. Os principais representantes do núcleo do Rio foram: 1) os professores veteranos, Everardo Backheuser, Fernando Antônio Raja Gabaglia, João Capistrano Raja Gabaglia, Silvio Fróis de Abreu, Carlos Delgado de Carvalho; 2) os franceses Pierre Deffontaines e Philipe Arbos; 3) os alunos Hugo Segadas Viana, Christóvam Leite de Castro (que na época já atuava como engenheiro, professor de cartografia na UDF, secretário do CNG/IBGE), Orlando Valverde, Jorge Zarur, Fábio Macedo Soares Guimarães (na época já engenheiro geógrafo) e Hilgard Sternberg ${ }^{15}$. É o período do grande impulso da Geografia como ciência moderna no Rio de Janeiro orientada pela escola francesa lablachiana, principalmente a partir da atuação de Delgado de Carvalho e de Pierre Deffontaines. Jorge Zarur inicia sua formação geográfica nesse momento, recebendo a influência francesa, que continuaria nas duas décadas subsequentes ${ }^{16}$.

No início dos anos 40, em função dos problemas advindos da Segunda Guerra, há um relativo declínio da tradição de pensamento francês na Geografia brasileira, principalmente no Rio de Janeiro. As atividades da União Geográfica Internacional (UGI), espécie de matriz francesa, ficam temporariamente suspensas, levando o $\mathrm{CNG} / \mathrm{IBGE}$ a estreitar relações com organizações congêneres americanas, como a American Geographical Society e o Instituto Pan-americano de Geografia e História (IPGH), ligado à Organização dos Estados Americanos (OEA). Embora o Brasil tenha se associado ao IPGH desde o ano de sua fundação, em 1928, na Sexta Conferência Internacional

\footnotetext{
14 VALVERDE, Orlando 1992, p.118-120.

15 MACHADO, Mônica, 2009, p.71.

${ }^{16} \mathrm{O}$ importante geógrafo Francis Ruellan, por exemplo, chega no Rio em 1941, aqui ficando 15 anos, atuando na Universidade e no IBGE, até 1956. Philipe Arbos também em 1939 e ficando até 1945, para lecionar na Universidade do Brasil. (MACHADO, Mônica, 2009, p.61 e p.133)
} 
Americana em Havana, retirou-se temporariamente entre 1940 e 1944, quando retomou sua adesão a partir da iniciativa de Christóvam Leite de Castro, em visita a sede do IPGH no México, para tratar da realização da II Reunião Pan-americana de Consulta sobre Geografia e Cartografia que aconteceria no Rio de Janeiro no mesmo ano ${ }^{17}$.

Não apenas no período da Guerra, mas durante toda a década 40 e a de 1950, a influência norteamericana vai se estabelecendo e se ampliando no País. Nesse período vieram para cá os norteamericanos Robert Platt (1944), Clarence Fielden Jones (1948), Preston James (1949) e Lynn Smith (1952) e o importante geógrafo alemão, com cidadania americana, Leo Waibel $(1946)^{18}$. Vale lembrar que um pouco antes de vinda desses profissionais, em 1943, Jorge Zarur havia convivido com Clarence Jones, Preston James e Robert Platt, em Washington, DC, na então National Planning Association, e com Leo Waibel, na Universidade de Wisconsin-Madison, quando lá cursava sua pós-graduação, entre 1941-1943 ${ }^{19}$. Zarur, assim, exerceu um papel articulador na vinda desses profissionais. Para ilustrar sua atuação e exemplificar a singularidade da influência norte-americana recebida pelo Brasil no período, resultado do cruzamento da Geografia alemã e norte-americana com ênfase econômica e política, vale a pena trazer aqui um breve relato sobre a ida de Waibel para os Estados Unidos, que lá ficou por cinco anos entre 1939-1945, assim como o episódio do estreitamento de relações entre Waibel e Zarur.

Em finais da década de 1930, Waibel já exercia grande influência na Geografia alemã e na Geografia norte-americana. Entretanto, como consequência da política nazista nos que antecederam a Segunda Guerra, Waibel foi demitido e proibido de exercer quaisquer funções em universidades na Alemanha, em 1937, assim como inúmeros pesquisadores alemães. Com auxílio de um de seus ex-alunos, Karl J. Pelzer, em 1939, Waibel transferiu-se para os Estados Unidos e foi nomeado pesquisador associado (1939-1941), por intervenção de Isaiah Bowman. Reconhecido na Geografia norte-americana e

${ }^{17}$ PENHA, Eli, Alves, 1993, p.89

${ }^{18}$ No mesmo período estiveram também no Rio o canadense Pierre Dansereau, (1946), os franceses Max Sorre (1947), Lucien Febvre (conferências, 1949), Pierre Deffontaines (1952, 1953 e 1956) e o alemão Carl Troll (1953 e 1956) (MACHADO, Mônica, 2009, p.111)

${ }^{19}$ ZARUR, Jorge. A Geografia: ciência moderna a serviço do homem. RBG, IBGE, 1944, v.6, n3, p.316-317 
internacionalmente, Bowman atuava como consultor especial do presidente Franklin Roosevelt, coordenando o "Project M" (Migration), do qual seu ex-aluno também participava. O projeto propunha o estudo das possibilidades de aldeamento no mundo inteiro, excetuando o território dos Estados Unidos, para imigrantes judeus e para a esperada onda de refugiados europeus depois da Guerra. Waibel vai trabalhar neste projeto ficando responsável pela América Central, para a identificação geográfica dos países e das regiões ainda não habitadas e de áreas apropriadas para o povoamento de imigrantes europeus. Este trabalho se refletiu posteriormente em suas pesquisas sul do Brasil e no Espírito Santo.

Em 1941, Waibel passou a lecionar na Universidade de Madison, no estado de Wisconsin, assumindo até 1944, o lugar de Richard Hartshorne, que havia sido convocado a cumprir serviços militares ${ }^{20}$. É justamente nesse período que conhece e orienta Jorge Zarur, tendo sido um dos seus melhores alunos, conforme o próprio depoimento de Waibel ${ }^{21}$. Por intermédio de Carlos Delgado de Carvalho, Zarur havia conseguido uma bolsa de estudos de pós-graduação para Universidade de Wisconsin-Madison, indo para lá em 1941 e estudando com Glenn T. Trewartha e V. C. Finch e Léo Waibel, que o viram como um importante elo ligação com a América Latina ${ }^{22}$. Quando Zarur retorna de Wisconsin, em 1943, traz um convite do Governo americano para a ida de mais cinco geógrafos com bolsas de estudo $^{23}$.

Em 1945 seguiram, então, para os Estados Unidos: Fábio de Macedo Soares Guimarães e Orlando Valverde, para a Universidade de Wisconsin-Madison, no estado de Wisconsin; Lúcio de Castro Soares e Lindalvo Bezerra dos Santos; para a Universidade de Chicago, no estado de Illinois, e José Veríssimo da Costa Pereira, para Universidade de Northwestern, em Evanston, estado de Illinois. Fábio de Macedo Soares Guimarães e Orlando Valverde transmitem o convite oficial do CNG/IBGE para Waibel vir ao Brasil desempenhar a tarefa de consultor científico. Apesar de Waibel ter adquirido

\footnotetext{
${ }^{20}$ KOHLHEPP, Gerd. 2013, p.32-34.

${ }^{21}$ Carta de recomendação de Leo Waibel para Jorge Zarur, concedida quando Wailbel lecionava no Departamento de Geografia da Univ ersidade de Wisconsin- Madison, em janeiro de 1943. (Acervo Marcela Zarur).

${ }^{22}$ Carta de recomendação de Finch para Jorge Zarur, janeiro de 1943 e Carta de recomendação de Glenn T. Trewartha para Zorge Zarur, janeiro de 1943.

${ }^{23}$ AMEIDA, Roberto S., 2000, p.485.
} 
cidadania norte-americana em 1945, ele não havia conseguido entrar no quadro de efetivos da Universidade e aceita o convite do Governo brasileiro, vindo para o Rio de Janeiro trabalhar no CNG/IBGE. A cidadania americana para ele foi de grande utilidade, pois logo depois do final da Guerra, na condição de cientista alemão, não teria podido assumir um cargo de consultor do Governo brasileiro $^{24}$. Da mesma forma, a atuação articuladora de Zarur nos Estados Unidos ajuda a explicar a primeira aproximação da Geografia norte-americana com o Brasil.

\section{Jorge Zarur: vida, obra e influências}

Jorge Zarur (1916, Rio de Janeiro - 1957, Rio de Janeiro) nasceu no bairro de Botafogo. Primeiro filho do casal migrante sírio-libanês que chegou ao Brasil no final da primeira década do século XX, Chade Jorge Zarur (Libano) e Helena Elias Zarur, (Síria, Hayfa) e foi morar na colônia sírio-libanesa no Saara, centro da cidade do Rio de Janeiro. Seu pai tornou-se um comerciante bem-sucedido e um dos líderes da colônia libanesa no Rio de Janeiro. Na década de 1930, apoiou financeiramente a campanha de Júlio Prestes, perdendo dinheiro, expressão política local e mudando-se para o bairro do Meier, zona norte da cidade ${ }^{25}$.

Na época Jorge Zarur já era aluno da instituição de ensino público mais importante do País, o Colégio Pedro II. Lá estudou o curso de humanidades, entre 1929 e 1934, formando-se em Bacharel em Ciências e Letras e conheceu seus primeiros mestres da Geografia, Fernando Antonio Raja Gabaglia e Delgado de Carvalho ${ }^{26}$. Posteriormente, ingressou no Curso de Direito e no Curso de Geografia da então Universidade do Distrito Federal, formando-se em ambas carreiras, em 1940, na já Universidade do Brasil, universidade que incorporou os cursos da antiga Universidade do Distrito Federal $^{27}$.

\footnotetext{
${ }^{24}$ KOHLHEPP, Gerd. 2013, p.33.

${ }^{25}$ ZARUR, Marcela, 2015, p.24.

${ }^{26}$ GUERRA, Antonio Teixeira, 1958.

${ }^{27}$ MACHADO, Mônica, 2009, p.70.
} 
No Curso de Geografia, Zarur foi aluno dos professores Pierre Deffontaines, Phillippe Arbos, Delgado de Carvalho e Fernando Antônio Raja Gabaglia e colega de Curso de Hugo Segadas Viana, Christóvam Leite de Castro, Orlando Valverde e Fábio Macedo Soares Guimarães ${ }^{28}$. Entre 1936 e 1941 foi assistente de Delgado de Carvalho e Fernando Raja Gabaglia no Colégio Pedro II.

Sua primeira influência e sua formação vieram da Geografia francesa lablachiana, da qual Deffontaines e o próprio Delgado de Carvalho eram grandes entusiastas. Como pode ser observado na fotografia da Figura 1, retirada do livro de Lévi-Strauss, Saudades do Brasil, que apresenta a reconstituição das viagens do antropólogo no território brasileiro, entre 1935 e 1939. Nessa fotografia, de 1937, estão Jorge Zarur, Emmanuel de Martonne e René Courtin. Segundo Levi-Strauss, De Martornne, improvisava uma aula aula sobre a paisagem que parecia uma admirável interpretação de texto. Um dos mais importantes geógrafos franceses do período, diretamente filiado à escola lablachiana, De Martonne estava no Brasil realizando levantamentos geomorfológicos, lecionando na USP e apoiando a criação do Conselho Nacional de Geografia. O economista René Courtin, assim como Levi Strauss fazia parte da missão universitária francesa e lecionava também na USP. Zarur estava no segundo ano do Curso de Geografia na Universidade do Distrito Federal, no Rio de Janeiro, e possivelmente havia ido para São Paulo assistir aulas com o mestre francês.

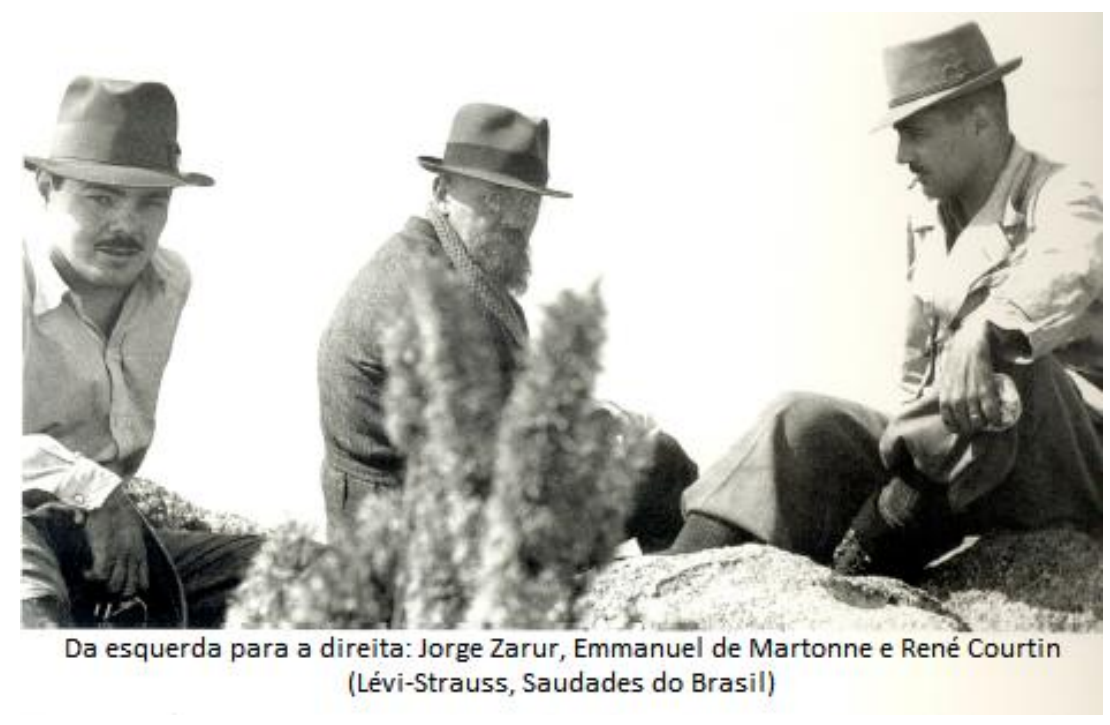

\footnotetext{
${ }^{28}$ MACHADO, Mônica, 2009, p.71.
} 
Figura 1. Zarur, De Martonne, Courtin

Em 1937 o CNG/IBGE estava em formação a partir da iniciativa do embaixador Carlos Macedo Soares Guimarães, na época Ministro das Relações Exteriores de Vargas, posteriormente Presidente do IBGE, e do apoio de Christóvam Leite de Castro, que se tornaria o primeiro Secretário-geral do CNG/IBGE ${ }^{29}$. Leite de Castro convida Orlando Valverde para Secretário Assistente do CNG tendo sido o primeiro geógrafo contratado em $1938^{30}$. Inicialmente o Conselho era constituído por engenheiros e por alguns geógrafos treinados por Deffontaines e Delgado de Carvalho nas primeiras turmas da Universidade do Distrito Federal, dentre eles estavam: Fábio de Macedo Soares Guimarães (sobrinho de Carlos Macedo Soares Guimarães) ${ }^{31}$, contratado em 1938, e Jorge Zarur, contratado em 1939, aos 23 anos. Mais dois geógrafos em seguida ingressaram também, José Veríssimo da Costa Pereira e Lúcio de Castro Soares, em $1940^{32}$.

Assim, Zarur foi um dos pioneiros da criação do CNG/IBGE ${ }^{33}$. Em 1940, tornou-se sócio titular da Sociedade de Geografia do Rio de Janeiro participando da organização do IX Congresso Brasileiro de Geografia, realizado nesse mesmo ano, em Florianópolis ${ }^{34}$. No Congresso apresentou seu primeiro trabalho Estudo sobre as caatingas e participou da Comissão Técnica de Metodologia Geográfica, Regras e Nomenclatura, coordenada por Delgado de Carvalho. Além de analisar os trabalhos do Congresso, esta comissão se debruçou sobre a renovação da Geografia, discutindo e propondo roteiros e planos de excursões, delimitações para regiões naturais do território brasileiro, publicação de mapas didáticos e a separação a dos cursos de Geografia e História, que em 1939, na Universidade do Brasil passaram a estar unidos ${ }^{35}$.

${ }^{29}$ ALMEIDA, Roberto S. 2000, p.78.

${ }^{30}$ ALMEIDA, Roberto S. 2000, p.78.

${ }^{31}$ GEIGER, Pedro, 2001.

${ }^{32}$ ALMEIDA, Roberto S. 2000, p.154.

${ }^{33}$ GUERRA, Antonio Teixeira, RBG, 1958, v 20, n 3, p.318.

${ }^{34}$ ZARUR, Marcela, 2015, p.27.

${ }^{35}$ RBG, IBGE, 1940, v.2, n.4, p.630. Sobre a separação dos cursos de Geografia e História na universidade no Rio de Janeiro, ver

MACHADO, Mônica, 2009, p.63-64 e p.138-148. 
No ano de 1941, a Revista Brasileira de Geografia (RBG), do CNG/IBGE, publicou o texto elaborado por Zarur, A Geografia no Curso Secundário ${ }^{36}$. Trata-se de um estudo descritivo e amplo, com 42 páginas, abordando a modernização da ciência geográfica no Brasil e a história da Geografia e do ensino de Geografia na Europa, Estados Unidos e Brasil. Proposições para a renovação do ensino da Geografia no País são apresentadas por Zarur. O autor inicia seu texto defendendo a renovação da Geografia, uma Geografia científica e moderna, orientada pelos estudos práticos e pela explicação, em substituição aos estudos descritivos do período. Fez uma recuperação da história da Geografia desde os gregos até La Blache e seus discípulos, buscando as relações com o ensino desta ciência. Destaca a contribuição de Delgado de Carvalho e Fernando Antonio Raja Gabaglia na modernização do ensino geográfico no Brasil. Em seguida explora a situação do ensino da Geografia no curso secundário, buscando discutir os propósitos e as práticas do conhecimento geográfico nesse segmento. Fez um levantamento do ensino de Geografia nos Estados Unidos, Inglaterra, Alemanha, França e Brasil, desde o ensino básico ao superior, apontando as influências que cada país recebeu e estabelecendo algumas comparações. Novamente a figura e o trabalho de Delgado de Carvalho e Raja Gablagia são aqui sublinhados, como grandes responsáveis pela implantação da moderna e e científica Geografia no Brasil, principalmente, Delgado de Carvalho. Por Fim apresenta propostas que incluem aspectos técnicos, didáticos, de infraestrutura, de atividades práticas em sala da aula, etc. para 0 desenvolvimento da Geografia no curso secundário no Brasil.

Ainda em 1941, Zarur escreveu para a Revista Brasileira de Geografia um pequeno texto de quatro

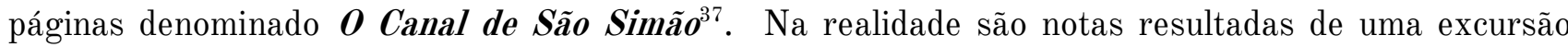
patrocinada pela Revista para a região do Triângulo Mineiro e o, então, Canal São Simão, no sul do Rio Parnaíba, divisa do estados de Minas Gerais e Goiás. Zarur faz uma descrição do relevo da região do Rio Paranaíba e mostra a especificidade do São Simão, destacando suas características geomorfológicas e hidrográficas e apresentando uma hipótese para explicação de sua origem e

\footnotetext{
${ }^{36}$ ZARUR, Jorge. A Geografia no Curso Secundário, RBG, IBGE, 1941, v.3, n.2,p.227-269.

${ }^{37}$ ZARUR, Jorge. Comentários: O Canal São Simão. RBG, IBGE, 1941, v3, n3, p.621-625. O Canal São Simão foi inundado posteriormente, em 1975, pela Central Elétrica de Minas Gerais (Cemig), com o represamento das águas para a barragem de São Simão. São Simão ficava ao sul da então cachoeira Dourada, que também foi destruída em meados da década de 50, para dar lugar à Usina Hidrelétrica de Cachoeira Dourada, pelo acordo do Governo Federal com a Centrais Elétricas de Goiás (Celg).
} 
formação. Duas observações podem ser feitas a partir desse pequeno texto de Zarur. A primeira voltada para a dinâmica científica da Geografia, com destaque para a preocupação do autor em buscar uma explicação "científica" sobre a formação hidrográfica e geomorfológica da área. A segunda voltada para a política, especialmente, a política territorial do Governo federal à época, que tinha interesses na construção da nova capital brasileira no interior do Brasil. Para tanto, era necessário realizar estudos locacionais e avaliação do potencial energético de manutenção da nova cidade. A área visitada por Zarur foi uma das escolhidas para a localização da nova capital e oferecia um grande potencial energético, dado pelo conjunto de quedas-d'água da região. Na segunda metade da década de 1940, o IBGE foi convocado oficialmente pelo Governo para definir possíveis localizações para a nova capital no Planalto Central. Duas esquipes foram organizadas, uma coordenada por Leo Waibel e outra por Francis Ruellan ${ }^{38}$.

Em setembro de 1941, Zarur vai para Universidade de Wisconsin-Madison, Estados Unidos, realizar o Curso de Mestrado com Glenn Thomas Trewartha e Vernor Clifford Finch e Leo Waibel, com uma bolsa de estudos concedida por Delgado de Carvalho, que havia recebido por aquela universidade para um de seus alunos ${ }^{39}$. Na viagem conheceu Cecília de Cerqueira Leite, que se torna sua esposa ${ }^{40}$. A Figura 2 apresenta parte de um trecho da carta escrita por Delgado de Carvalho, em homenagem póstuma ao Jorge Zarur, 1957.

\footnotetext{
38 "Na questão da localização da futura capital, o debate se estabeleceu aparentemente por conta de duas posições divergentes, ocorridas durante o final de 1947 e início de 1948. De um lado, osgeógrafos que defendiam uma localização no Triângulo Mineiro (...). Do outro lado, os geodesistas, militares e a bancada dos estados do Nordeste viam com muito interesse a opção do Espigão Mestre, em área próxima a cidade de Formosa em Goiás." (ALMEIDA, Roberto S. 200, p.110-111)

${ }^{39}$ Carta de Carlos Delgado de Carvalho à Jorge Zarur, após sua morte, 1957. Acervo Marcela Zarur

${ }^{40}$ De família paulista, Cecília nasceu em Curitiba e veio para o Rio, formando-se em Direito na Faculdade Nacional. Seu irmão, Nélio Cerqueira Gonçalves, era Coronel da Policia Militar de Minas Gerais, tendo sido seu comandante nos anos iniciais da década de 1950. Filiado ao PSD (Partido Social Democrático), mesmo partido de Juscelino, Nélio tornou-se assessor especial de JK durante seu Governo, apoiando-o e contando com seu apoio durante todo seu mandato. "Não é exagero dizer que a posse de JK deve-se, em boa parte, ao dispositivo militar organizado em Minas, no tempo em que as polícias militares eram exércitos estaduais, que pesavam decisivamente no jogo político do País." (Depoimento concedido por George de Cerqueira Leite Zarur, filho de Jorge Zarur, à Marcela Zarur, 2015. ZARUR, Marcela, 2015). Talvez por influência de Nélio, Jorge Zarur acabou se aproximando muito do PSD, principalmente, durante a década de 1950, apoiando as articulações e a política de Juscelino. Isso pode explicar tanto a aproximação com Josué de Castro (que era do PTB, partido aliado à Juscelino), que participou de várias reuniões com Zarur quando o acirramento dos conflitos internos no IBGE em função da oposição política entre os geógrafos da UDN (opositores de JK) e os do PSD, durante a década de 1950.
} 


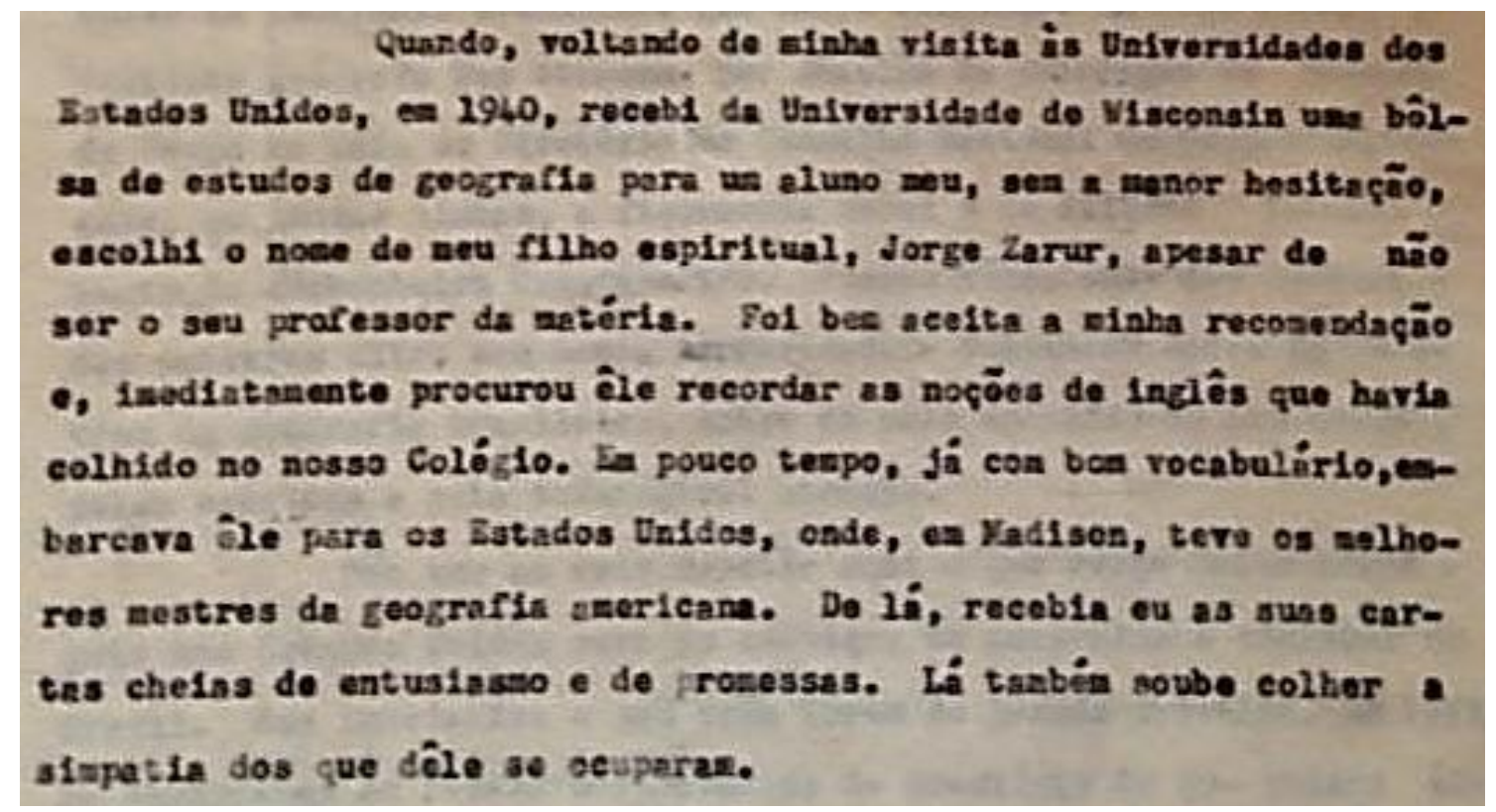

Figura 2. Trecho da Carta Delgado de Carvalho, março de $1957^{41}$

Entre setembro de 1941 e janeiro de 1943, Zarur ficou nos Estados Unidos realizando seu mestrado, cursando disciplinas e se formando com esses três mestres da escola regionalista e com professores vinculados à ciência econômica, como Richard T. Ely e Georg S. Wehrwein. As cartas de recomendação que Zarur traz de Trewartha e Finch e Waibel, escritas em janeiro de 1943, apresentam algumas disciplinas cursadas e destacam o aprimoramento de sua formação, especialmente no campo da economia, de grande importância para a escola regionalista norte-americana. As figuras 3, 4 e 5 são pequenos trechos dessas cartas que ilustram o início da formação e influência dessa dessa matriz geográfica em Jorge Zarur.

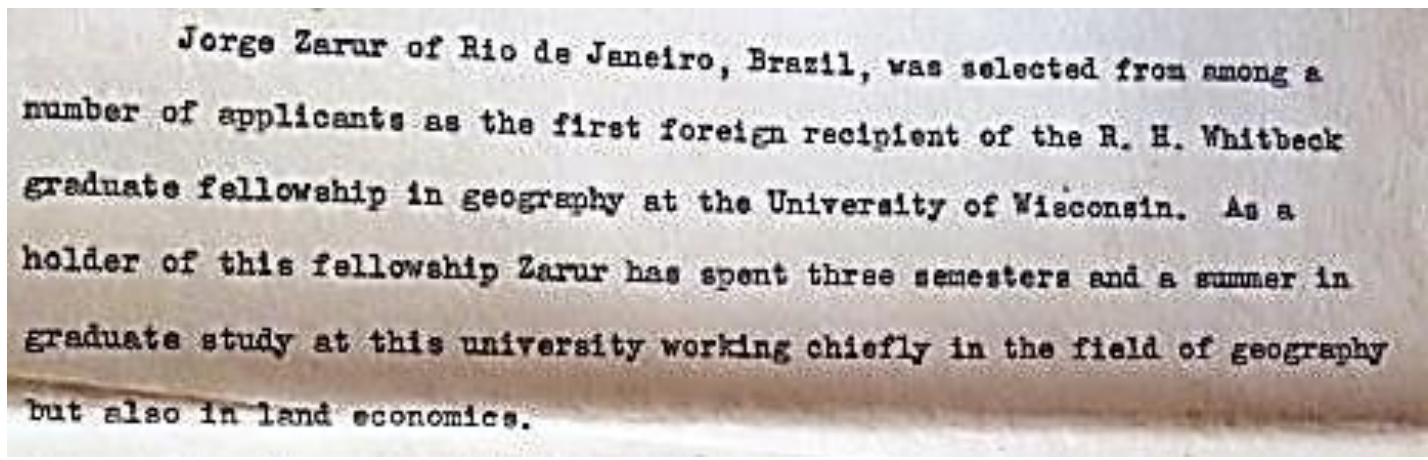

Figura 3. Trecho da Carta de Recomendação a Jorge Zarur, de Glenn Thomas Trewartha,1943. ${ }^{42}$

\footnotetext{
${ }^{41}$ Carta de Carlos Delgado de Carvalho a Jorge Zarur, após sua morte, 1957. Acervo Marcela Zarur.
} 
This 1 s to certify that Mr. Jorge Zarur has been a postgraduate student and $n$ cnndidate for hicher doeress in Eoocraphy at the Univoralty of Wiscomsin botween the dates of September 15, 1941 and Jamary 25, 1943. During his residence hare $\mathrm{Kr}$, Zarur has purgued studles in various aspecta of geography, both physical and cultural, and in certain related 11elda, particularly land conomics. H1a geographical atudies hare inoluded erpecially geomorphology, phyalcal and regional climatology, reglonal economlo geography and geographlcal technlques, such as fiold ongreg methoda end. cartography. Doring this time ho has been granted the degree of vaster of

Figura 4. Trecho da Carta de Recomendação a Jorge Zarur, de Vernor Clifford Finch, 1943. ${ }^{43}$

Thio 1 s to certify that Mr. Jorge Zarar has been a postgraduate student and $n$ cnndidate for hicher doereas in Eoocraphy at the Univoralty of Wisconsin botween the dates of September 15, 1941 and Jamary 25, 1943. During his residence here $\mathrm{Kr}$, Zerur hag pursued studles in vartous aspecta of geography, both physical and cultural, and in certain related l1elda, particularly land eonomics. H1a geographical atudies hare included erpeoially geomorphology, phyalcal and regional cllmatology, reglonal economio geography and geographlcal techniques, such as flold onereg methoda end cartography. Durting this time he has been granted the degree of vaster of

Figura 5. Trecho da Carta de Recomendação a Jorge Zarur, de Leo Waibel, $1943 .{ }^{44}$

Durante o mestrado, no outono de 1942, Zarur realizou ainda um curso na Universidade de Chicago acerca dos modernos métodos de Geografia de Campo. Exerceu também importante papel de aproximação e divulgação da Geografia norte-americana no Brasil. A Revista Brasileira de Geografia, entre 1942 e 1943, publicou três resenhas elaboradas por Zarur de obras de autores que tomou contato e estudou em Wisconsin. São elas: Latin America, de Preston James, 1942; Geopolitics - The

\footnotetext{
${ }^{42}$ Carta de Recomendação a Jorge Zarur, de Glenn Thomas Trewartha,1943, 1943. Acervo Marcela Zarur.

${ }^{43}$ Carta de Recomendação a Jorge Zarur, de Vernor Clifford Finch, 1943. Acervo Marcela Zarur.

${ }^{44}$ Carta de Recomendação a Jorge Zarur, de Le Waibel,1943. Acervo Marcela Zarur.
} 
Strugle for space and power, de Robert Strasz-Hupé, 1942; e, Um comentário sobre a classificação

de Köppen, 1943. Em 1944, quando já havia concluído seu mestrado, Zarur comenta ainda o trabalho

Land Economics, de Richad T. Ely e Georg S. Wehrwein (NY), este último havia sido seu professor em Wisconsin. Os textos escritos por Zarur foram listados e estão organizados no Quadro 1.

\begin{tabular}{|c|c|c|}
\hline & Títulos dos textos e livros escritos por Zarur & Referências \\
\hline 1940 & Estudo sobre as caatingas & IX Congresso Brasileiro de Geografia, Florianópolis (Anais) \\
\hline 1941 & A Geografia no Curso Secundário & RBG, 1941, v.3, n.2,p.227-269 \\
\hline 1941 & Comentários: O Canal São Simão & RBG, 1941, v3, n3, p.621-625. \\
\hline 1942 & Latin America, Preston James, por Jorge Zarur & RBG, 1942 v4 n3. Pág 587-600 \\
\hline 1942 & $\begin{array}{l}\text { Geopolitics - The Strugle for space and power } \\
\text { Robert Strass, por Jorge Zarur }\end{array}$ & RBG 1942 v4 n4, p.848-852 \\
\hline 1943 & $\begin{array}{l}\text { Um comentário sobre a classificação de Köppen, por } \\
\text { Jorge Zarur }\end{array}$ & RBG 1943 v5 n2, p.250-254 \\
\hline 1944 & Geografia: ciência moderna ao serviço do homem & RBG 1944 v6 n3, p.313-326 \\
\hline 1944 & $\begin{array}{l}\text { Land Economics, Richad T. Ely e Georg S. } \\
\text { Wehrwein (NY), por Jorge Zarur }\end{array}$ & RBG 1944 v6, n4, p.546-550 \\
\hline 1946 & Análises Regionais & RBG 1946 v8, n2, p.177-188 \\
\hline 1946 & $\begin{array}{l}\text { A Bacia do Médio São Francisco: uma análise } \\
\text { regional. }\end{array}$ & Serviço Gráfico do IBGE, 1946. \\
\hline 1948 & $\begin{array}{l}\text { Geografia e Cartografia para fins censitários na } \\
\text { América Latina }\end{array}$ & RBG, 1948 v10, n4, p.561-598 \\
\hline 1955 & Precisão e Aplicabilidade na Geografia & $\begin{array}{l}\text { Tese apresentada em concurso par a cátedra de Geografia Geral e do } \\
\text { Brasil, Colégio Pedro II, Rio de Janeiro, 1955, 153p. }\end{array}$ \\
\hline
\end{tabular}

Quadro 1. Quadro com textos e livros escritos por Zarur, entre 1940 e 1955.

No mesmo volume e número da RBG que foi publicada a resenha Latin America, de Preston James, elaborada por Zarur, são também editados mais dois textos sobre a Geografia nos Estados Unidos. Geography in American Universities, de Rafael Picó, de Porto Rico, comentado por Francis Ruellan, e Economic Geography, de Clarence Jones e Gordon Darkenwald, comentado por Sampaio Ferraz. O primeiro apresenta as características da Geografia desenvolvida nos centros universitários norteamericanos e suas principais influências ao longo do tempo. O segundo divulgava a Geografia econômica feita nos Estados Unidos na época, assentada na nova concepção regionalista. Esta concepção passava a relacionar os fatores físicos do meio ambiente às condições econômicas da ocupação produtiva e à distribuição dos produtos. Propunha também um novo método regional, conduzido pela classificação ocupacional e não pelo produto ou pelas características físicas da região, 
que passavam a aparecer nas suas subdivisões. Nesse método, particular destaque eram dados às indústrias, localizando-as e classificando-as, e à dinâmica e o impacto do mercado mundial. Assim, diferentemente da proposição francesa lablachiana, a economia regional defendida por Clarence Jones passava a entender e analisar a região na sua relação com o mundo, principalmente a partir da economia.

A obra de Preston James, Latin America, veiculava também essa nova Geografia regionalista que estava sendo feita nos Estados Unidos fazendo um grande levantamento e análise regional da América Latina com objetivo político de defender a ideia de América, do Novo Mundo, reforçando o papel e a importância latino-americana. Já Geopolitics - The Strugle for space and power, de Robert StraszHupé, cientista político austríaco que havia migrado para os Estados Unidos em 1923, tornando-se professor da Universidade da Pensilvânia, publicado em 1942, analisava os escritos de Haushofer e outros da escola alemã de Geopolítica demonstrando a influência na política nazista e a necessidade dos Estados Unidos fazerem uso dos seu métodos e informações para vencer a Guerra. Zarur apresenta esses dois textos ao Brasil reforçando a abordagem econômica e política na Geografia.

Outro texto trazido por Zarur para o Brasil, em 1943, que passava a ser utilizado nesses estudos regionais como base para o estabelecimento das relações ambientais às condições econômicas das regiões, foi a classificação climática proposta pelo russo Waldimir Köppen, em 1900 e aperfeiçoada até 1936, com nova versão e edição, Um comentário sobre a classificação de Köppen, conforme mencionado no Quadro $1^{45}$. Na realidade Köppen propunha um sistema de classificação global associando biomas e tipos climáticos. Preston James utiliza esse sistema de classificação para estabelecer e discutir as novas divisões regionais no seu livro, Latin America.

\footnotetext{
45 Os professores de Zarur em Wisconsin Clifford Finch e Glenn Thomas Trewartha haviam publicado um extenso livro denominado Elementos de Geografia em 1936, muito utilizado por todas as áreas da Geografia. A maior parte desse livro tratava dos elementos naturais da paisagem, principalmente do clima do tempo, e classificava os tipos de clima e sua distribuição. Posteriormente, em 1954, Trewartha publica Uma Introdução ao Clima tendo sido muito utilizado nos departamentos de Geografia nos Estados Unidos. Aqui propunha alterações na classificação de Köppen estabelecendo uma nova classificação, derivada da de Köppen, passando a ser bastante conhecida e utilizada.
} 
Em 1944 é o livro Land Economics, editado em 1940, que Zarur vai comentar. Este livro havia servido de texto no curso que realizou em Winscosin, com um dos seus autores, Wehrwein. Na realidade land economics ou economia da superfície terrestre havia surgido com os economistas e com os adeptos da conservação dos recursos naturais nos Estados Unidos, no tempo de Theodore Roosevelt e Van Hise, e seus sistematizadores foram justamente os autores do livro comentado por Zarur. O livro apresentava grande preocupação com a utilização da terra, do ponto de vista econômico. Defendia a necessidade de estabelecer uma área de estudo dedicada ao planejamento e uso da terra do ponto de vista produtivo, o que incluía considerar variáveis como propriedade da terra, políticas públicas, povoamento, produção, circulação e comercialização dos produtos e infraestrutura de transportes. Zarur apresenta um panorama da obra e chama atenção para duas proposições teóricas: o sistema de classificação do uso da terra dos autores do livro e a teoria de localização agrícola do economista alemão Von Thünen. Eram proposições que estabeleciam classificações para regionalizações das atividades produtivas. Essas proposições foram apresentadas ao Brasil por Zarur e representaram uma inovação na forma do fazer geográfico no País naquele momento. Embora ainda dominando procedimentos indutivos e dedutivos, naquele momento eram introduzidas não apenas interpretações mais abstratas que indicavam a adoção de procedimentos dedutivos na metodologia da Geografia, mas também uma nova visão sobre a pesquisa geográfica aplicada e voltada ao planejamento territorial.

Essa última resenha foi elaborada por Zarur um ano após ter concluído seu curso de mestrado em Wisconsin. Nota-se o amadurecimento intelectual do autor e clara assimilação ao conteúdo dos seus cursos realizados nos Estados Unidos. Podem ser também aqui verificadas tanto a defesa de uma Geografia aplicada e útil para o planejamento territorial público, em prol da otimização econômica na utilização do espaço geográfico, quanto a defesa de uma Geografia renovada mais dedutiva, valorizando aspectos socioeconômicos e estabelecendo uma nova forma de regionalização e de concepção de região. Esses temas foram também tratados por Zarur na palestra de abertura do X Congresso Brasileiro de Geografia em 1944, Geografia: ciência moderna ao serviço do homem, transcrita e publicadas no mesmo ano na RBG, e por ele aprofundados e aplicados nos estudos realizados posteriormente como, Análises Regionais, A Bacia do Médio São Francisco: uma análise 
regional, em 1946, Geografia e Cartografia para fins censitários na América Latina, em 1948, e Precisão e Aplicabilidade na Geografia, em 1955.

Para esse amadurecimento intelectual, o ano de 1943 foi particularmente importante na vida e obra de Zarur, marcando também o estreitamento dos laços com a Geografia norte-americana e a aplicação dessa orientação em seus estudos geográficos posteriores. Foi em 1943 que Zarur concluiu seu curso de mestrado em Wisconsin, iniciou um intercâmbio cultural entre CNG/IBGE e American Geographical Society (AGS), Nova Iorque, e a ele associando-se, passou a representar o CNG no Instituto Panamericano de Geografia e História (IPGH), começou a trabalhar na National Planning Association de Washington, D C, realizou estudos e pesquisas de campo no Vale do São Francisco, para esta instituição. Assim, em 1943, Zarur não só passou a fazer várias viagens no Eixo BrasilEstados Unidos se constituindo como importante elo de ligação entre as geografias de ambos os países, como também passou a se dedicar ao ao estudo da América Latina, que posteriormente, resultou na preparação do primeiro censo das Américas 1950.

O intercâmbio cultural entre o Brasil e Estados Unidos, acima mencionado, foi concluído por Cristóvão Leite de Castro, na época Secretário Geral do CNG/IBGE, e John Wright, então Diretor da AGS. Nele ficou estabelecida a permissão da recíproca divulgação dos artigos e comentários veiculados entre a Revista Brasileira de Geografia (RBG -revista editada pelo $\mathrm{CNG}$ ) e a Geographical Review (revista editada pela $\mathrm{AGS})^{46}$. O que explica o número de artigos norte-americanos publicados na RBG nesse período. Na National Planning Association de Washington, D C, Zarur passou a trabalhar em um grande projeto que abrangia toda a América Latina, sob orientação de Clarence Jones, permitindo maior conhecimento do uso da Geografia como instrumento da administração, da guerra e do capital ${ }^{47}$. Trabalhou nesse projeto durante 18 meses, até final do ano de 1944, dando início a elaboração de sua principal obra a Bacia do Médio São Francisco: uma análise regional, publicada em livro, em 1946.

${ }^{46}$ RBG, IBGE, Notíciário.1943, v5, n1. p.140

${ }^{47}$ ZARUR, Jorge. A Geografia: ciência moderna a serviço do homem, RBG, 1944, v6, n3, p.316-317. 
Este livro, na realidade, trata-se de um relatório elaborado por Zarur para a National Planning Association. Era o terceiro relatório de sete preparados para o escritório de Nelson Rockefeller pelo Latin-Americna Regional Resources Project, da National Planning Association. Seu objetivo era levantar e analisar os recursos e os meios de vida da Bacia do Médio São Francisco e indicar direções para o desenvolvimento da agricultura, potencial da floresta e recursos humanos para a região ${ }^{48}$. $\mathrm{Na}$ época, uma região com problemas econômicos sérios encravada dentro do Brasil, pouca explorada e seus potenciais econômicos pouco conhecidos. Era um estudo regional aos moldes da então escola regionalista que se estruturava que teve como modelo o planejamento territorial da bacia do Tennesse, executado pelo Tennsesse Valley Authority (TVA) na década de 30. Uma Geografia aplicada ao planejamento econômico territorial.

O livro apresenta ricos e numerosos dados, gráficos, informações e mapas da região, frutos de levantamentos realizados em arquivos, bibliotecas e no campo, distribuídos por quatro capítulos. Sua estrutura é bem interessante, pois ilustra a metodologia dessa análise regional. O primeiro capítulo apresenta a localização e caracterização da Bacia do São Francisco. O segundo é dedicado as características da população, seu meio de vida e ocupação. O terceiro, denominado pelo autor de Fatores que afetam a encomia regional, expõe as características naturais, econômicas e politicais, que, segundo Zarur, afetam a região. O último apresenta algumas proposições de intervenção na região, sendo denominado pelo autor de Diretrizes para um reajustamento desejável. Conforme Zarur, ali estava, a bacia da Esperança. Este livro é um material de consulta exemplar, não apenas do ponto de vista metodológico da análise regional, como igualmente para a memória e estudo da região.

Associado ao estudo da Bacia do São Francisco, outro trabalho escrito por Zarur que merece ser comentado é Análises Regionais, publicado pela RBG, em $1946^{49}$. Trata-se de um texto teórico onde são apresentadas e discutidas não apenas as definições de região e de análise regional, mas também os métodos de regionalização e algumas proposições para realização da análise regional e do planejamento

${ }^{48}$ ZARUR, Jorge. A bacia do médio São Francisco: uma análise regional. Serviço Gráfico do IBGE, 1946.

${ }^{49}$ ZARUR, Jorge. Análises Regionais. RBG 1946 v8, n2, p.177-188 
regional no Brasil, assunto muito pouco comum nos estudos geográficos no País naquela década. Sustentado, principalmente, em Hartshorne, Bowman e Odum, Zarur propõe o conceito de região bastante diferente do conceito que predominava então, dando particular destaque para os aspectos socioeconômicos e ao dinamismo regional. Orientação evidente no estudo do Médio São Francisco.

Ainda no ano de 1946, Zarur começou a se envolver na preparação dos planos destinados a realização do primeiro censo das Américas 1950, com apoio e patrocínio do Pan-Americano de Geografia e História (IPGH), do Escritório de Assuntos Interamericanos (o Office of the Coordinator of InterAmerican Affairs, de responsabilidade de Rockefeller), do Instituto Brasileiro de Geografia e Estatística (IBGE) e do Instituto Interamericano de Estatistica (IASI) ${ }^{50}$. Os objetivos deste projeto era identificar mapas para fins censitários nas nações americanas, com exceção dos Estados Unidos e Canadá, realizar consultas e deliberar com cartógrafos e estatísticos desses países sobre os mapas adequados à realização censitária, especificamente de dados relativos à população e agricultura. Dessa forma, seria possível atender aos padrões internacionais da época, uniformizando e compatibilizando os resultados com outras nações ${ }^{51}$.

Zarur era responsável pela realização do estudo da situação cartográfica da América Latina ${ }^{52}$. Além de pesquisar as coleções de mapas existentes nos Estados Unidos e no Brasil, as quais abrangem muitos países latino-americanos, Zarur visitou as nações latino-americanas para o levantamento e catalogação das instituições responsáveis pela elaboração e confecção de mapas, assim como de seus acervos. A partir desse levantamento e dos contatos estabelecidos, pôde conhecer as características e as necessidades geográficas e cartográficas de cada país e propor recomendações técnicas necessárias

\footnotetext{
${ }^{50}$ Em cumprimento das resoluções tomadas no Primeiro Congresso Interamericano reunido no México, em 1943, o IASI assumiu a realização dos trabalhos preparatórios para execução de um Censo Geral de População nos países do continente americano, em 1950. (IBGE CONSELHO NACIONAL DE ESTATÍSTICA, SERVIÇO NACIONAL DE RECENSEAMENTO. Resoluções do Comitê do Censo das Américas de 1950. Documentos Censitários, série D, n.4, Rio de Janeiro, 1953)

51 Desde a segunda metade do século XX, o Brasil participava de Congressos Internacionais de Estatística e das seções periodicamente promovidas pelo Instituto Interamericano de Estatística (IASI), com objetivo de desenvolver e compatibilizar as estatísticas oficiais no âmbito das Américas, assegurando a uniformidade de conceitos, do qual dependia a comparabilidade dos resultados dos censos das nações americanas. O Recenseamento de 1950, 1960, 1970, 1980 levado a efeito no País estava dentro das orientações do Censo das Américas, em atendimento a uma solicitação específica da ONU. (IBGE - MEMÓRIA. Disponível em: http://memoria.ibge.gov.br/sinteses-

historicas/historicos-dos-censos/censos-demograficos.html. Acesso 13 de novembro de 2014).

${ }^{52}$ IBGE - CONSELHO NACIONAL DE ESTATÍSTICA, SERVIÇO NACIONAL DE RECENSEAMENTO. Resoluções do Comitê do Censo das Américas de 1950. Documentos Censitários, série D, n.4, Rio de Janeiro, 1953.
} 
ao êxito do censo das Américas, conforme pode ser conferido no seu relatório, veiculado na RBG em 1948, Geografia e Cartografia para fins censitários na América Latina ${ }^{53}$.

Após a realização das atividades do Censo das Américas 1950, Zarur começou a dar aulas nos cursos de Geografia Regional e Cartografia na Universidade do Brasil, em 1951, lecionando até 1955. Na Universidade, Zarur trabalhou com Josué de Castro, então catedrático de Geografia Humana, com quem estabeleceu relações acadêmicas e políticas ${ }^{54}$. Em 1955, Zarur prestou concurso para a cátedra de Geografia Geral e do Brasil do Colégio Pedro II com a tese Precisão e Aplicabilidade na Geografia, último trabalho por ele editado.

Nesse estudo, Zarur apresentou ideias sobre região e métodos de análise, com utilização de fotografias aéreas, desenvolvidas nos Estados Unidos em Syracuse, em 1954. Defendeu a necessidade de detalhamento no mapeamento de campo com emprego da fotografia aérea, o que permitia maior precisão, essencial para aplicabilidade dos estudos geográficos. Tratou também de defender a modernização do ensino de Geografia nos cursos secundários e universitários com a inclusão não apenas dessas novas concepções e análises regionais, como também das modernas técnicas e recursos de mapeamento.

Dois anos depois, em 1957, com 41 anos, Zarur faleceu. Pouco antes de sua morte, havia iniciado um novo projeto e criado o Centro de Treinamento Pan-Americano para Avaliação dos Recursos Naturais, em parceria com a Organização dos Estados Americanos (OEA ${ }^{55}$.

\footnotetext{
${ }^{53}$ ZARUR, Jorge. Geografia e Cartografia para fins censitários na América Latina. RBG, 1948 v10, n4, p.561-598.

${ }^{54}$ (MACHADO, Mônica, 2009, p.111-112, p.115). Assim como Zarur, Josué de Castro teve influência de Preston James. Manteve contato com James desde a década de 1930, absorvendo concepções teóricas que aparecem em parte sua obra. Josué intermediou a tradução de um dos livros de James, An Outline of Geography, feita por Eric Veríssimo. Por sua vez, Preston James prefaciou o livro de Josué de Castro, Geogafia Humana, estudo da paisagem cultural do mundo. Em 1948, na direção do Departamento de Geografia da Universidade do Br asil, Josué também convidou James para ministrar curso na Universidade. (CARVALHO, Antonio A.T. de 2001). Quanto a relação de Zarur com Josué, conforme depoimento de seu filho George Zarur, Josué e Zarur mantinham constante contato, estando sempre presente em reuniões na casa de Zarur (Depoimento concedido por George de Cerqueira Leite Zarur, filho de Jorge Zarur, à Marcela Zarur, 2015. ZARUR, Marcela, 2015). É interessante observar também o agradecimento feito a Zarur por Josué no prefácio da edição de 1960 de sua obra Geografia da Fome:"Ao saudoso Professor Jorge Zarur pela prestimosidade com que ajudou a seleção e a inclusão nestes volumes do material ilustrativo retirado dos arquivos do Conselho Nacional de Geografia”.

${ }^{55}$ ZARUR, Marcela, 2015.
} 


\section{CONSIDERAÇÕES FINAIS}

A partir de uma extensa base documental, este artigo buscou apresentar e explorar um fragmento da história da Geografia no Brasil, ainda muito pouco conhecido principalmente, pelas novas gerações de geógrafos do País. Como parte de uma agenda de pesquisa maior, sobre a história e memória da Geografia brasileira, este trabalho procurou trazer um conjunto de informações detalhadas sobre um momento e um personagem da Geografia, explorando e contextualizando suas contribuições e obras, no sentido não apenas de organização documental da memória desta ciência, mas sobretudo de oferecer elementos para uma reflexão sobre o fazer geográfico, para uma reflexão epistemológica.

A opção pela análise da Geografia a partir de um momento e de um indivíduo, não se contrapõe àquelas realizadas com base nos movimentos dos grandes paradigmas geográficos, mas sim procura adicionar novas informações e interpretações. A primeira aproximação da Geografia feita nos Estados Unidos com a Geografia no Brasil aconteceu em finais da década de 1930 e, sobretudo na década de 1940, portanto, em um período de predomínio da Geografia positivista clássica, e no caso brasileiro, de matriz francesa. Nesse sentido a Geografia feita no Brasil espelhou essa influência. Não significando afirmar, contudo, que autores e estudos do período constituíssem um bloco monolítico, rígido e homogêneo. Há pontos comuns entre eles, que os identificam ao seu tempo, mas há diferenças e singularidades e só uma análise mais detalhada pode revelá-las. Este trabalho é um exemplo. Procurou demonstrar a ocorrência de outra matriz geográfica nos estudos brasileiros em um período em que dominava a interpretação geográfica francesa lablachiana, assim como destacar a participação de um importante personagem nesse contexto, Jorge Zarur.

Zarur foi um homem do seu tempo. Soube aproveitar bem as oportunidades e as novas frentes de trabalho que se abriam, associadas à ideia de América, do Novo Mundo, e ao pan-americanismo estadunidense que surgia com intensidade no pós Segunda Guerra. Zarur atuou como um articulador importante na aproximação da Geografia brasileira com a Geografia norte-americana. Foi um excelente técnico do planejamento regional, sendo o responsável pela sua introdução no País, defendendo claramente uma Geografia aplicada e útil para o planejamento público territorial, evidentes 
em seus estudos, textos e palestras. Sua capacidade de gestão também merece menção, evidente no projeto do Censo das Américas, 1950.

No âmbito pedagógico, dedicou-se à renovação da Geografia no ensino escolar e universitário. Defendeu a introdução de uma Geografia científica, mais dedutiva e menos limitada às descrições empíricas. Apresentou ao Brasil um novo conceito de região e de regionalização, estabelecidos pelo cruzamento da Geografia norte-americana e alemã, apoiados não nas características naturais, mas sim associadas às atividades econômicas, à ocupação e à estrutura agrária e fundiária. A regionalização começava a ser estabelecida não mais pelas características fisiográficas da região, mas por suas características socioeconômicas e suas articulações com outras regiões. Defendeu também a modernização das técnicas de mapeamento, de trabalho de campo e a utilização das fotografias aéreas como recurso fundamental para ampliar a precisão das observações de campo e dos mapeamentos.

A Geografia defendida por Zarur nas décadas de 1940 e 1950 foi precursora da Geografia Tópica e da nova Geografia Regional de matriz norte-americana, que se desenvolveram no Brasil, na década de 1960, resultando nos estudos sobre região polarizada e homogênea. Resultaram também na difusão das práticas neopositivistas introduzidas, inicialmente, no Rio de Janeiro, centro político do País naquele momento, pelo IBGE. Zarur faleceu em 1957, em meio às disputas que dividiam o Brasil e o IBGE no que se referem às decisões e articulações da política nacional e do planejamento territorial ${ }^{56}$.

\section{REFERÊNCIAS}

\footnotetext{
${ }^{56}$ Ao longo da década de 1950, os conflitos e disputas político-partidárias foram intensas no IBGE. Essas desavenças internas acabaram provocando uma crise na Instituição, com vários processos administrativos, que na realidade parecem refletir problemas da política nacional. No IBGE, havia o grupo próximo à UDN, representado por Fábio Macedo Soares, Lysia Bernardes, Nilo Bernardes, (mais chegados aos franceses) e o grupo próximo ao PSD, representado por Jorge Zarur e Speridião Faissol (mais chegados aos norte-americanos). O clima era de tensão e de muitas desavenças entre ambos os grupos, quando Zarur faleceu. Embora seja necessária uma investigação maior, assunto para outro estudo, analisar essas disputas parece ser um caminho interessante de pesquisa, uma vez que elas parecem estar associadas à política nacional, na época também dividida entre o PSD, que estava aliado ao PTB, e a UDN. O PSD aglutinava as correntes mais conservadoras, formada por proprietários rurais e por altos funcionários estatais. O PTB aglutinava as lideranças sindicais e os operários fabris em geral. De outro havia o partido comunista, mas que desde 1947 estava com seu registro cassado, e a UDN. A UDN era um partido liberal e antipopulista, composto pela alta burguesia e a classe média urbana, defensora do capital estrangeiro e da iniciativa privada, tendo sido a principal promotora das impugnações das vitórias eleitorais da coligação PSD-PTB nos cinco primeiros anos da década de 50 e a maior instigadora das tentativas de golpes não apenas contra Getúlio Vargas, mas também contra Juscelino Kubitschek, Jânio Quadros e João Goulart.
} 
ALMEIDA, Roberto S. A geografia e os geógrafos do IBGE no periodo de 1938-1998. Orientador: Lia Osório Machado. Rio de Janeiro, 2000. Tese (Doutorado em Geografia), Universidade Federal do Rio de Janeiro.

BERNARDES, Nilo. A influência estrangeira no desenvolvimento da Geografia no Brasil. Revista Brasileira da Geografia. Rio de Janeiro: IBGE, ano 44, n.3, 1982. p.519-528.

CARVAlHO, Antonio A. T. de. Josué de Castro na Perspectiva da Geografia Brasileira-1934-1956: uma contribuição à historiografia geográfica nacional. Dissertação de Mestrado. Orientador José Borzacchiello da Silva, 2001.

GEIGER, Pedro Pinchas. Entrevista realizada por Mônica Machado, 2001.

http://www.grupogeobrasil.com.br/usuario//pedro_geiger//pedro_geiger_geobiografia_2.pdf)

GUERRA, Antonio Teixeira. Vultos da Geografia do Brasil, Jorge Zarur. 1958, v 20, n 3, p.315-318.

GOMES, Horiestes. Jorge Zarur, “um geógrafo moderno”. Boletim Goianio de Geografia, 17 (1): 47-52, jan./jun.1997.

KOHLHEPP, Gerd. A importância de Leo Waibel para a geografia brasileira e o início das relações científicas entre o Brasil e a Alemanha no campo da geografia. Revista Brasileira de Desenvolvimento Regional. Blumenau, 1 (2), p. 29-75, 2013.

MAGNANO, Angélica Alves. A divisão regional brasileira. Uma revisão bibliográfica. Revista Brasileira de Geografia. Vol. 57, n. 4. 1995. pp. 65-92.

MACHADO, Mônica Sampaio. A construção da geografia universitária no Brasil. Rio de Janeiro: Apicuri, 2009.

MENDONÇA, Sônia Regina de. As bases do desenvolvimento capitalista dependente: da industrialização restringida à internacionalização. Maria Yedda Linhares (org) História Geral do Brasil. Editora Campus, 1990, p.327-350

MOURA, Gerson. Relações exteriores do Brasil: 1939-1915, mudanças na natureza das relações Brasil-Estados Unidos durante e após a Segunda Guerra Mundial. Brasília: FUNAG, 2012. 277.

MORAES, Antonio Carlos Robert. Memorial apresentado ao concurso para preenchimento do cargo de professor titular no Departamento de Geografia da Faculdade de Filosofia, Letras e Ciências Humanas da Universidade de São Paulo, 2004, $71 \mathrm{p}$.

PENHA, Eli Alves. A Criação do IBGE no contexto da centralização política do Estado Novo. Cadernos Memória Institucional. Rio de Janeiro: CDDI - IBGE, 1993, 124 p.

VALVERDE. Orlando. Pré-história da AGB carioca. Terra Livre. São Paulo: AGB, n.10, jan./jul., 1992. p. 117-122.

.Evolução da Geografia Brasileira no após-guerra: carta aberta de Orlando e Orlando. Boletim Paulista de Geografia. n. 60. São Paulo, 1984. p.5-20.

VELOSO FILHO, Francisco. Análises Geográficas do espaço regional: referências conceituais, metodológicas e estudos aplicados no Brasil. Revista Equador (UFPI), Vol. 4, № 1 (Edição Especial 1), p.1-180 (Jan./jun., 2015).

ZARUR, Jorge. A Geografia no Curso Secundário. RBG, 1941, v.3, n.2, p.227-269.

. Noticiário: O Canal de São Simão. RBG, 1941, v3 n3. p.621-625.

. Latin America. Revista Brasileira de Geografia, Rio de Janeiro, volume 4, n.3, p. 587-600, jul. set. 1942 (Resenha do livro JAMES, Preston E. Latin America. New York: Odissey Press, 1942). 
. A Geografia: ciência moderna a serviço do homem. RBG 1944, v.6, n3, p.313-326

. Land economics. Revista Brasileira de Geografia, Rio de Janeiro, volume 6, n.4, p. 106 -110, out. dez. 1944

(Comentários sobre o livro de autoria de Richard T. Ely e George S. Wehrwein, New York, MacMillan, 1940).

A bacia do médio São Francisco: uma análise regional. Serviço Gráfico do IBGE, 1946.

Análises regionais. Revista Brasileira de Geografia, Rio de Janeiro, volume 8, n.2, p. 3-11, abril junho 1946.

. Precisão e Aplicabilidade na geografia. Tese apresentada em concurso par a cátedra de Geografia Geral e do Brasil,

Colégio Pedro II, Rio de Janeiro, 1955, 153p.

ZARUR, Marcela. Jorge Zarur e a Geografia Brasileira. Documento de qualificação de mestrado, PPGEO-UERJ, 2015, $59 \mathrm{p}$.

\section{Documentos}

ASSOCIAÇÃO DOS GEÓGRAFOS BRASILEIROS, SÃO PAULO (AGB-SP). Anais da AGB: 1945-1946. São Paulo: AGB, v.1, 1949 .

IBGE - CONSELHO NACIONAL DE ESTATÍSTICA SERVIÇO NACIONAL DE RECENSEAMENTO. Resoluções do Comitê do Censo das Américas de 1950. Documentos Censitários, série D, n.4, Rio de Janeiro, 1953.

IBGE - MEMÓRIA. Disponível em: http://memoria.ibge.gov.br/sinteses-historicas/historicos-dos-censos/censosdemograficos.html. Acesso 13 de novembro de 2014.

REVISTA BRASILEIRA DE GEOGRAFIA, IBGE, Comentários IX Congresso Brasileiro de Geografia, pela Secretaria Geral do CNG. RBG 1940, v.2, n.4, p. 622-638.

REVISTA BRASILEIRA DE GEOGRAFIA, IBGE, Noticiário. Sociedade Brasileira de Antropologia e Etnologia (SBAE), RBG, 1941, v3, n3. p.711.

REVISTA BRASILEIRA DE GEOGRAFIA, IBGE, Noticiário. 1943, v5, n1. p.140.

CARTA DE LÉO WAIBEL para Zarur, Janeiro de 1943. Wisconsin. Acervo Marcela Zarur.

CARTA DE RECOMENDAÇÃO DE FINCH para Jorge Zarur, janeiro de 1943 e Carta de recomendação de Glenn T. Trewartha para Zorge Zarur, janeiro de 1943.

CARTA DE CARLOS DELGADO de Carvalho à Jorge Zarur, após sua morte, março de 1957. Acervo Marcela Zarur. 